\title{
La conspiración como arma política. El plan sedicioso del 14 de agosto de 1833 en Cartagena
}

\author{
Edwin Monsalvo Mendoza \\ Universidad de Caldas \\ edwin.monsalvo@ucaldas.edu.co \\ Jorge CONDE CALDERÓN \\ Universidad del Atlántico \\ jorgeconde1@mail.uniatlantico.edu.co
}

Recepción: 2 de marzo de 2011 / Revisión: 15 de marzo de 2011

Aceptación: 19 de mayo de 2011 / Publicación: diciembre de 2011

\begin{abstract}
RESUMEN
Este artículo examina el tema de las conspiraciones en la primera mitad del siglo XIX en la actual Colombia. En particular, se concentra en el análisis del expediente judicial que resultó de la causa seguida a más de los cincuenta implicados, en su mayoría artesanos, en la conspiración del 14 de agosto de 1833 en la ciudad de Cartagena. Aunque el proceso judicial subrayó móviles raciales, la naturaleza festiva del suceso, así como las adscripciones políticas de los inculpados y sus necesidades socioprofesionales, inserta las conspiraciones en una pugna política entre facciones en la que tan importante como la acción sediciosa, fue la invención o la magnificación de la misma a partir de referentes compartidos por la comunidad.
\end{abstract}

Palabras clave: Conspiración, sedición, racial, proceso judicial, Cartagena, Colombia, siglo XIX.

Conspiracy as a Political Weapon. The Seditious Plan of August 14, 1833 in Cartagena

\begin{abstract}
This article examines the issue of conspiracy in the first half of the nineteenth century in what is now Colombia. In particular, it focuses on the analysis of court records pertaining to the lawsuit against the over fifty persons involved -mostly artisans- in the conspiracy of August 14, 1833 in the city of Cartagena. Although the judicial process highlighted racial motivations, the festive nature of the event, the political affiliation of the defendants and their socio-professional needs inserted the conspiracies within the framework of a factional political struggle, in which the invention or magnification of the conspiracies, based on references shared by the community, were as important as the seditious actions themselves.
\end{abstract}

Keywords: Conspiracy, Sedition, Racial, Judicial Process, Cartagena, Colombia, 19th Century.

SUMARIO: 1. La recomposición del orden político. 2. Del ritual del bautismo al de la conspiración. 3. El mito de la conspiración construido con aguardiente. 4. La "guerra de razas": entre el rumor y el temor. 5. Conclusiones. 6. Referencias bibliográficas. 
Tras la instauración de la República de Colombia en 1821 (Gran Colombia para los historiadores) las elites gobernantes creyeron haber logrado la estabilidad política necesaria para iniciar la construcción del Estado y consolidar las instituciones. Sin embargo, la lucha entre facciones, las conmociones políticas, la desobediencia al gobierno central, las dictaduras que se cernían sobre los gobiernos provincial o nacional legítimamente constituidos y el rumor de conspiraciones urdidas por los diferentes bandos políticos constituyeron hechos que complicaron ese proceso. En las provincias del litoral caribeño todo lo anterior fue acompañado de imaginarias insurrecciones de pardos, mulatos y negros organizadas desde Jamaica o los Cayos contra la clase de los notables blancos.

En medio de ese clima de exacerbación política se forjó y extendió la idea de que ser opositor o crítico frente al gobierno era equivalente a sedicioso o conspirador ${ }^{1}$. Al final, la unidad grancolombiana, si en realidad había logrado funcionar en algún momento como república unitaria y centralizada, se disolvió y a partir de 1830 , los territorios que la conformaban se convirtieron en repúblicas independientes: Venezuela, Nueva Granada y Ecuador. En las tres la inestabilidad política y el conflicto faccionalista permaneció latente, pasando a ser la ingobernabilidad su común denominador, principalmente en aquellas provincias alejadas del centro político-administrativo.

En la República de la Nueva Granada, la provincia de Cartagena exigía la atención especial y permanente del gobierno central radicado en Bogotá, por su composición social en la que el elemento racial fue determinante. Consecuencia de ello fue que los gobernadores provinciales dedicaron el mayor tiempo de su administración al sostenimiento del orden público. No tanto al referido a la corrección del comportamiento en las calles y espacios públicos, como al concerniente a la vigilancia de las conductas privadas de algunos individuos considerados desafectos a la causa liberal y promotores de actos conspirativos o rebeldes, por lo que se les mantuvo en constante vigilancia policial para averiguar sus planes. En buena medida, el evento político que se aborda en este trabajo y el proceso judicial que generó, permite seguir y analizar las estratagemas empleadas por el gobierno provincial para frenar posibles planes de conspiración. Los rumores sobre sediciones contra el gobierno contribuyeron a debilitar la oposición, ya que favorecían el desarrollo de medidas coercitivas y castigos ejemplarizantes que permitían el debilitamiento y hasta la eliminación de los adversarios políticos. Además, quienes ejercían el gobierno se valieron del poder legal de los magistrados y de la fuerza armada para formar una opinión pública favorable con respecto a las medidas punitivas adoptadas y ejecutadas en nombre del Estado.

Por conspiración se entiende en este texto un plan que busca la desestabilización o eliminación del gobierno local o nacional, a través de estrategias de difusión de in-

${ }^{1}$ La idea de planes conspirativos permeó el imaginario iberoamericano entre finales del siglo XVIII y los primeros decenios del siglo XIX. El tema ha sido estudiado en el Brasil bajo la dominación portuguesa por LOCKHART - SCHWARTZ, 1992, pp. 378 y ss; BETHELL, 1991, pp. 178-185. La conspiración venezolana de Juan Picornell, Manuel Gual y José María España ha despertado el mayor interés de los historiadores, véase: GRASSES, 1997; interesante por la incorporación de las mujeres blancas, pardas y negras en esa trama conspirativa es el ensayo de Troconis, 1997, pp. 3-21. El decenio de 1840 fue rico en conspiraciones de esclavos en Cuba y Puerto Rico: Baralt, 2006, pp. 81-100. 
formación tendenciosa con pasquines o libelos infamatorios, pero en el cual también se emplea la fuerza armada para lograr el objetivo trazado. Hay que tener en cuenta que el éxito o fracaso de un movimiento conspirativo dependía de la convicción de sus organizadores, la selección de personas políticamente afines y un plan ajustado táctica y estratégicamente ${ }^{2}$. En el caso de los cartageneros acusados de conspiración, la mayoría de los elementos planteados anteriormente no estuvieron presentes. Aunque fuesen opositores al gobierno central y local, ello no implicaba necesariamente que hubiesen organizado una conspiración según lo antes expuesto. Sin embargo, el gobierno y sus magistrados concluyeron que se fraguaba una conspiración y ello permitió no solo deshacerse de algunos adversarios políticos, sino también silenciar a la oposición.

En los eventos conspirativos de Cartagena, la presencia y participación de los sectores populares fue importante, sobre todo la de aquellos identificados como pardos, mulatos o negros. Las razones por las que se involucraban en tales proyectos eran variadas. Si en algunos casos su intervención obedecía a motivaciones estrictamente políticas, en otros respondía a un criterio de solidaridad de gremio (artesanos, masones o clubes políticos), estando los móviles económicos, relativos a la reclamación de los menestrales de medidas para mejorar su nivel material, en relación con demandas de estatus social. Con independencia de la naturaleza de sus reclamaciones, todos los involucrados tenían en común que pertenecían o estaban vinculados por una red de favores a una facción política que conspiraba como medio para garantizar su permanencia en el poder o su acceso al mismo; acto que habitualmente se ejercía después de unas elecciones. En la mayoría de los casos, los objetivos de las conspiraciones no se materializaban porque éstas eran descubiertas, pero ello no impedía que se desestabilizara al gobierno de turno al tener éste que dedicar sus esfuerzos a desenmarañar la red de los supuestos conspiradores. Si bien su éxito estaba definido por el derrocamiento definitivo del gobierno, los conspiradores también se planteaban otros propósitos menores para presionar a éste de cara a un proceso de negociación y transacción destinado a la obtención de garantías políticas o beneficios locales, como apoderarse de un arsenal, asaltar un cuartel militar o amotinarse.

Los castigos para los acusados de conspiración eran severos y ejemplarizantes como el destierro, el encierro o la pena de muerte. El primero solía llevar usualmente al condenado a Venezuela o a una isla del Caribe y era considerado como una pena de suplicio ya que cortaba todos los lazos familiares y de amistad de la persona. Como la cárcel en la Nueva Granada no era muy segura y ofrecía cierta facilidad para la fuga ${ }^{3}$, para

${ }^{2}$ Girardet, 1986, pp. 32-33.

${ }^{3}$ Sobre las cárceles de Barranquilla véanse las narraciones de Isaac Holton un viajero que recorrió el país en la década del cincuenta del siglo XIX quien manifestó que "también visité la cárcel de la provincia que es un salón con dos cuartos a cada lado. El guardián o alcalde es zapatero y estaba ocupado en su oficio. Era el primer hombre que veía trabajar desde mi llegada a la Nueva Granada, fuera de otros dos, que vi aserrando unas tablas, para lo cual utilizaban un tosco artefacto que les permitía elevar uno de los extremos de la troza, en tal forma que uno de los hombres casi podía pararse debajo. La prisión no estaba ni muy llena ni muy limpia, pero lo peor era que las ventanas de los dos cuartos daban a la calle. Todas las cárceles aquí están construidas con materiales poco seguros, tierra apisonada o ladrillos sin cocer, y claro está, la estada del prisionero en semejante pocilga, depende en gran parte de su buena voluntad". Holton, 1981. Ver también: Vidal - Monsalvo, 2008. 
los acusados de sedición y conspiración estaban reservados los presidios más seguros y crueles del país, como los localizados en los castillos de Cartagena y Chagres en Panamá, cuya sola mención causaba temor por las condiciones climáticas e insalubres que prácticamente aseguraban que una larga condena se convirtiera en una lenta pena de muerte. Finalmente, la ejecución se realizaba en la plaza pública tras la publicación de un bando para asegurar la concurrencia del pueblo, de tal manera que no solo se acababa con un enemigo del gobierno sino que además se hacía "pedagogía ciudadana".

Este trabajo analiza una conspiración descubierta por el gobierno provincial de Cartagena y cuya supuesta finalidad consistía en generar un cambio de gobierno. Debía estallar la noche del 14 agosto de 1833, pero las autoridades recibieron oportunas denuncias que llevaron a la captura de más de cincuenta implicados liderados por el capitán de milicias Cirilo Pomares. Pese a que éste se dio a la fuga, fue capturado y juzgado posteriormente. Tal evento conspirativo será estudiado como una de las estrategias gubernamentales empleadas durante el período de transición entre 1828 y 1834, que transcurrió entre el final del gobierno de Bolívar en la República de Colombia y el inicio del de Santander en la nueva e independiente República de la Nueva Granada. En el caso escogido, se trataba de excluir a la oposición "bolivariana" o "servil" -como era llamada por los liberales simpatizantes de Santander- compuesta por los afectos a Bolívar. No se olvide que en Cartagena, la rivalidad entre el vicepresidente de la República, general Francisco de Paula Santander, y el presidente Simón Bolívar fue férrea. Ello dio lugar a que se armasen facciones muy polarizadas alrededor de las dos figuras, trasladándose con igual vehemencia la animosidad de cada uno de sus frentes de oposición a sus conmilitones o simpatizantes. Atendiendo a ese contexto, las conspiraciones se entenderán como un arma política; por lo que se describirá cómo se construyó y usó el mito del hombre conspirador, del sedicioso, del instigador de guerras raciales para justificar su prisión, expulsión o aniquilamiento. El trabajo se divide en tres partes, en la primera se da cuenta del contexto político en el que se produce la conspiración; en la segunda, se analiza el desarrollo de la misma; y, en la tercera, se explica el papel que jugaron los sectores populares en ésta. Por último, se elucidan los sucesos y su influencia en la formación del Estado de la Nueva Granada.

\section{LA RECOMPOSICIÓN DEL ORDEN POLÍTICO}

Con la desaparición definitiva de la Grancolombia, los neogranadinos proyectaron organizar su propia forma de gobierno republicano. Esa identificación con la nación como comunidad política de pertenencia llevó a los notables bogotanos, cartageneros, payaneses, panameños, antioqueños, etc., a imaginarse como neogranadinos y a presentarse a la convención de finales de 1831 con los más diversos proyectos constitucionales liderados por los representantes de Bogotá, Popayán y Cartagena. Las discusiones estuvieron estructuradas por las pugnas entre los federalistas y centralistas sobre la forma del pacto $o$ acto de asociación. Así, por ejemplo, desde Popayán se envió un documento por intermedio de Joaquín Mosquera, en el cual se pedía trabajar por la Confederación Colombiana. La exposición de Mosquera recordaba, en algunas partes, la efímera Constitución 
del 29 de abril de 1830, sancionada por el vicepresidente Domingo Caicedo. Esta carta reconocía la autonomía de las provincias integrantes de Venezuela y la Nueva Granada. Sin embargo, la constitución no logró entrar en vigencia, pues el golpe militar de Rafael Urdaneta depuso a las autoridades elegidas por el congreso. El golpe originó en su contra la sublevación de los pueblos de la Nueva Granada en un movimiento que terminó con el retorno al gobierno de las autoridades depuestas. Sin embargo, el vicepresidente Domingo Caicedo reasumió el mando presidencial por abandono del titular Mosquera.

Los pronunciamientos de los pueblos de la Nueva Granada constituyeron un resurgimiento de los cuerpos intermedios de la representación eliminados por Bolívar desde 1828. En el Caribe colombiano, los pueblos pertenecientes a los cantones de Barranquilla y Soledad, de la provincia de Cartagena y algunos de la de Santa Marta, en el departamento del Magdalena, se pronunciaron en el "año del señor" de $1831^{4}$. El doce de febrero de 1831, los cantones de la provincia de Cartagena, Sabanalarga, Soledad y Barranquilla se levantaron en armas contra Mariano Montilla. El prefecto de Cartagena Juan de Francisco Martín capturó y expulsó a los "revoltosos" Manuel Marcelino Núñez y Enrique Rodríguez por instigadores. La acción armada estuvo coordinada por seiscientos efectivos militares de estas poblaciones que marcharon hacia el cantón de Soledad. Exigían la restitución de los derechos que habían conquistado por medio de muchos sacrificios y que habían sido arrebatados por un gobierno dictatorial. Para ellos, Cartagena era un bastión bolivariano en la Nueva Granada. Sin embargo, el comandante general del Departamento del Magdalena, Mariano Montilla envió tropas bajo el mando del general venezolano José Ignacio Luque quien rápidamente sofocó la revuelta. Días después, el mismo Luque encabezó una nueva rebelión que se extendió a Ciénaga, Santa Marta y Riohacha expulsando a Montilla, O'Leary, Carreño, Juan de Francisco Martín y otros afectos al libertador el 23 de abril de 1831. La comandancia militar quedó en manos de Luque y la gobernación en Manuel Romay. Mientras tanto, el anterior vicepresidente de Colombia, Domingo Caicedo, reasumió formalmente la presidencia ante la ausencia de Mosquera, luego de llegar a un convenio con Urdaneta, quien había renunciado a su cargo como presidente interino. En junio de 1831, todas las provincias reconocieron el gobierno de Caicedo, quien convocó a una convención de la Nueva Granada en octubre de ese mismo año. Esta convención expidió una Ley Fundamental de la Nueva Granada el 17 de noviembre de 1831 mediante la cual se reasignaba a Joaquín Mosquera como presidente de la nueva república.

Como el resto de la Nueva Granada, las provincias del Caribe fueron testigos de un rápido cambio político después de la victoria liberal de mayo de 1831. Los prisioneros santanderistas recuperaron su libertad y otros retornaron del exilio, entre ellos Manuel Marcelino Núñez. Tras reasumir sus derechos políticos se hicieron elegir favorecidos con el apoyo popular en las elecciones y ocuparon puestos en el gobierno ${ }^{5}$.

4 "Pronunciamiento de los cantones de Barlovento, Villa de Soledad, trece días del mes de febrero de año del señor de 1831", Imprenta de Manuel M. Guerrero, Cartagena de Colombia, 1831, Archivo General de la Nación (en adelante AGN), Archivo Restrepo, v. 170, ff. 171- 173.

${ }^{5}$ Véase Helg, 2004, p. 230. 
El gobierno central continuó recibiendo noticias acerca de la organización de un movimiento federalista en Cartagena ${ }^{6}$. Los primeros pasos para contrarrestar cualquier plan al respecto se dieron con la expulsión en abril de 1831 de muchos partidarios de Bolívar establecidos en Cartagena, de quienes se decía provenían tales ideas. Ese mismo año, el gobierno había enviado al coronel Montoya para que redujera el número de tropas acantonadas en la costa. Debido a la crisis económica que sufría Cartagena, el ejército representaba un importante medio de subsistencia para buena parte de la población, a la vez que la pertenencia a un cuerpo con fueros otorgaba reconocimiento social para la población parda y mulata que en su mayoría conformaba la tropa acantonada en la plaza ${ }^{7}$. Por tal razón cualquier medida que se tomara para licenciar a sus miembros era mal recibida aunque tuviese un carácter general. A esa disposición se sumó otra de carácter administrativo-territorial: el Congreso en octubre de 1831 abolió los departamentos como comunidades político administrativas y dictó su reemplazo por las provincias, así como la restitución de los cantones y distritos parroquiales. En la costa esto significaba, entre otras cosas, la perdida de autoridad de Cartagena sobre las provincias vecinas. Ello generó muchos inconvenientes para el desarrollo político y económico de la ciudad, además del recrudecimiento de los conflictos entre las ciudades del Caribe colombiano.

En 1832 asumió la presidencia de la Nueva Granada, Francisco de Paula Santander. A través de la Constitución de la Nueva Granada de 1832 promovió un proyecto estatal alternativo al bolivariano: menos centralista y que garantizara los privilegios y prebendas que sus elites gozaban desde la época colonial. Con su articulado respondía a una década anterior cargada de sucesos turbulentos resultado del reacomodo de las fuerzas políticas surgidas con las independencias y de la incapacidad del Estado central por sofocar las luchas de los distintos poderes locales ${ }^{8}$. Su administración, que duró hasta 1836, estuvo cargada de persecuciones contra los del partido de los "serviles". De tal manera que todos aquellos que habían demostrado simpatía por Bolívar, que en la provincia de Cartagena estaban representados por Montilla y Juan de Francisco Martín, fueron objeto de persecución y gran parte exiliados o fusilados. De ahí la preocupación de la administración Santander por perfeccionar la legislación sobre conspiradores. Mediante una ley de marzo de 1832, estableció el modo de proceder contra los reos de sedición, conspiración, rebelión o traición contra el Estado ${ }^{9}$. Se les castigaba con la muerte, la expatriación entre uno y cinco años o el presidio de dos a diez años dependiendo de la gravedad del delito. Los actos de los reos eran juzgados por el juez letrado de hacienda ${ }^{10}$. La última ley de la década de 1830 se expidió en ju-

\footnotetext{
${ }^{6}$ Para el desarrollo de la temática del federalismo véase: Conde - Monsalvo, 2010. También, ChiARAmonte, 2004, Carmagnani, 1993.

${ }^{7}$ Para la composición social del ejército de Cartagena o las milicias ver MARChEnA, 1982, pág. 506. Para lo de la crisis económica ver Kalmanovitz, 2008.

${ }^{8}$ Prado, 2005, p. 60.

${ }^{9}$ Codificación Nacional, Bogotá, Biblioteca Nacional, 1925. Tomo IV. Años de 1829, 1830, 1831 y 1832. Decreto 27-III-1832. "sobre el modo de proceder en los delitos de conspiración" (derogada por el artículo 37 de la ley del 3-VI-1833).

${ }^{10}$ Ibídem, p. 382.
} 
nio de $1833^{11}$. En esta se afirmaba que cuando el delito no se cometía en la capital de la provincia el caso podía llevarlo el juez letrado del cantón. Éste quedaba facultado para conducir a prisión a las personas que fueran denunciadas, pero también a aquellas sospechosas de tramar algo contra la seguridad pública ${ }^{12}$. Este procedimiento se debía realizar dentro de las primeras doce horas. A partir de allí, el juez debía expedir una orden de arresto por el delito de conspiración e incomunicar al preso con el público hasta el momento en que se le tomara la confesión. Asimismo, los artículos 27 y 28 definían a los conspiradores como aquellos que en secreto se reunían para cambiar la forma de gobierno, destruir las autoridades constituidas o desobedecerlas o auxiliar a los enemigos del país. También eran reos por conspiración quienes intentaran seducir a otros para complotar contra la autoridad o callaran ante las autoridades aún conociendo de planes en contra de la patria. Asimismo eran culpables los que esparcieran noticias falsas sobre los movimientos y el número de los enemigos, o sobre ideas contrarias al gobierno o el sistema establecido y los que tuvieran armas prohibidas ${ }^{13}$. Esta ley funcionó durante el decenio de 1830 y fue aplicada en el proceso judicial contra Cirilo Pomares y sus compadres.

\section{DEL RITUAL DEL BAUTISMO AL DE LA CONSPIRACIÓN}

En la noche del 14 de agosto de 1833, en la casa del señor Venancio Escalante ubicada en la calle del Jardín en la ciudad de Cartagena, se celebró un bautizo al que fueron invitados más de sesenta personas. Algunos de los asistentes declararon posteriormente que nunca llegaron a ver al niño que justificaba la fiesta, aunque permanecieron en la misma ante las amables atenciones del anfitrión. ¿Qué celebraban entonces? Eso era lo de menos. En la reunión todos se conocían, así que era un buen momento para departir y discurrir sobre política. Con el pasar de las horas y ante la abundancia de viandas dispuestas en una gran mesa llena de "licores de todas clases, pan y tabacos", que estaba estratégicamente ubicada en la mitad de la sala para la complacencia de todos los asistentes, éstos comenzaron a comentar los sucesos políticos locales y nacionales. En un clima de acaloramiento etílico el tema de conversación se fue desviando hacia las críticas a la administración provincial, especialmente hacia los llamados liberales. Con los ánimos caldeados, el dueño de la casa, el señor Venancio Escalante tomó la palabra e hizo un brindis por el "bien público" y todos lo siguieron. Seguidamente preguntó a los asistentes:

¿Ustedes sabrán en el estado en qué están las artes y no saben el por qué? Contestaron a esto los circunstantes que por hallarse la plaza tan escasa de dinero y en un

${ }^{11}$ Codificación Nacional, Bogotá, Biblioteca Nacional, 1925. Tomo V. Años de 1833, 1834 y 1835. 1925. Ley 3-VI-1833. "sobre el modo de proceder en las causas por sedición y conspiración” (derogada parcialmente por la ley del 30-V-1841) derogó a las leyes de 14-X-1821, del 27-V-1832 y los decretos de Simón Bolívar de 20-II y 15-III-1828.

${ }^{12}$ Ibidem, p. 30.

${ }^{13}$ Ibidem, art. 27 y 28 , pp. 33-34. 
estado deplorable; a lo que repuso que no era esa la razón pues consistía en ocho o diez blancos cuales eran Don Francisco Porras, y señores Agustín Argumedo, Francisco Veles, Manuel Marcelino Núñez ${ }^{14}$.

Después de los aplausos de los asistentes, ante el brindis de Escalante éste se atrevió a poner un ejemplo que da cuenta del cariz que había tomado el bautizo:

[...] si un blanco tenia un pleyto o le jugava a un negro una herida siempre el negro sometían en la cárcel y que con todo que conocieran la razón echaban al negro al presidio y el blanco se quedaba riendo y así que abriesen los ojos que estaban muy ciegos en consentir que los tuviesen tan sucumbidos ${ }^{15}$.

De su intervención resaltaban dos cuestiones: el dominio por parte de un grupo político de los recursos del Estado y la desigualdad social que ellos percibían en claro dominio de unas elites que se consideraban "blancas" y, por tanto, superiores.

Tras Escalante, tomó la palabra el señor Cirilo Pomares diciendo "Señores dejémonos de mas relaciones que el tiempo es corto, ya es hora Uds. me acompañan, a lo que respondieron todos que si", incluso los mismos que luego presentarían una denuncia sobre lo ocurrido ante el jefe político, argumentando que lo hicieron por temor a las represalias. Más tarde Pomares procedió a quitarse la chaqueta de capitán de milicias. Aunque ésta vestimenta no era la adecuada en un bautizo y menos sin estar de servicio, posiblemente su uso se debió a que era mulato o pardo y sentía la necesidad de mostrar su prestigio de la jerarquía militar en la sociedad. Tomó en la mano un aserrucho y pidió que Lauz "lo acompañase a su lado", luego sacaron un mazo de "cuchillos cacha blanca" y los repartieron entre todos. Hecho esto, salió Pomares con más de cuarenta y cinco compañeros armados con "cuchillos, cinceles y martillos", entre los cuales no se contaba el anfitrión de la fiesta que prefirió permanecer en su casa por el estado etílico en que se encontraba. El plan del capitán de milicias era tomar la guardia de San Pedro Mártir y hacerse con las armas del depósito, para luego llegar a las bóvedas donde había más armas y al final alcanzar la jefatura política del cantón ${ }^{16}$. Según Pomares para este plan contaba con los efectivos del presidio que lo respaldarían en cuanto iniciaran las revueltas ${ }^{17}$. Algunos de los concurrentes, como Pascual Alzamora, José María Lauz (los dos testigos denunciantes), Estanislao Franco, Andrés Jiménez, el zapatero José Conrado, Benito Herrera y José Maria Arestiguela, prefirieron retirarse mientras caminaban por las calles oscuras de la ciudad, ante lo cual Pomares les advirtió que si escuchaban algo extraño en la noche se

${ }^{14}$ Declaración de Pascual Alzamora y José María Lauz. Jefatura política municipal. Cartagena, 3:30 de la madrugada del 15-VIII-1833. A.G.N. Ministerio de lo Interior y Relaciones Exteriores, t. I, doc. 32 , f. 14 .

15 Ibidem.

16 Sobre los usos de los uniformes por los milicianos, véase: MARCHENA, 1990, p. 92: "There were many such officers in the American militia because the uniform accorded high prestige in urban society. Moreover, most of those who embraced the militia system did so to enjoy the benefits accorded by the fuero military."

17 Declaración de Cirilo Pomares. Juzgado letrado de hacienda. Cartagena, 17-VIII-1833. AGN, Ministerio de lo Interior y Relaciones Exteriores, t. I, doc. 32, f. 343. 
unieran a ellos. Un señor de apellido Pineda iba presidiendo la "multitud", lo seguían J. Francisco, Santos Pantoja, Juan Maria Mendosa, José Ramos, José Nicomedes Arroyo, Ysidoro de cuentas, - de quién decían estaba "malo de la cabeza"- Esteban Ycarrola, José Francisco Barco, su compadre el "Sambo Campañas", Antonio Gelis, Francisco Escalante (el barbero), Casimiro Castro, y un negrito inglés de oficio sastre que llamaban Bartolo ${ }^{18}$.

Después de retirarse de la manifestación conspirativa, pasadas las dos de la mañana, José María Lauz y Pascual Alzamora decidieron ir a la casa del jefe político a denunciar lo sucedido. Éste alertó a la guardia y avisó al juez letrado de hacienda, Ramón Ripoll, quien inmediatamente inició el trámite judicial y recibió las declaraciones de los testigos a tempranas horas del 15 de agosto de 1833. Éstas condujeron a la captura de: Venancio Escalante, Nicomedes Arroyo, Ysidoro de Cuentas, José Manuel Campaña, Felis Pineda, José Ramos, Manuel Paredes, José Santos Pantoja, Francisco Gonzáles, Estevan Ycarrola, Manuel Aguilar, Manuel Espíritu Santo Marques, José Francisco Barco, Manuel Pastor, José Ángel Fabrega, Antonio Abad Gelis, Juan Maria Mendoza, Andrés Jímenez, José Conrado De La O, Marcelo Morales, Andrés Díaz, Tomas Brun, Estanislao Franco, Santiago Arestigueta, Benito Herrera, José Herrera, Valentín Espitaleta y Casimiro Calvo. Todos ellos fueron buscados por el cargo de conspiración contra la administración de gobierno local, fraguada en la ciudad de Cartagena bajo las órdenes del capitán de milicias Cirilo Pomares, quién no pudo ser capturado el mismo día ${ }^{19}$. A las tres de la tarde del 16 de agosto también se llevó a cabo una pesquisa en la casa donde se había celebrado el bautizo con el objetivo de recoger "las armas o instrumentos que podían tener los conspiradores para llevar a cabo su proyecto" ${ }^{20}$. De esta pesquisa resultó la incautación de "dos cuchillos y un martillo, de las armas con que se proveyeron los que trataron de conspirar," y la captura de "hasta ahora veinte y cinco presos"21.

La investigación del caso se llevó con una celeridad que muestra que el gobierno de Santander no vacilaba a la hora de reprimir cualquier intento conspirador y menos en Cartagena donde la oposición a él era más fuerte. Y con mayor razón en el caso de un personaje como Cirilo Pomares, un artesano capitán de milicias con fama de "agitador profesional" por haber estado involucrado en los tumultos populares de $1828^{22}$. Además,

${ }_{18}$ Declaración de Pascual Alzamora y José María Lauz. Jefatura política municipal. Cartagena, 3:30 de la madrugada del 15-VIII-1833. AGN, Ministerio de lo interior y Relaciones Exteriores t. I doc. 32. f. 14. Véase también Informe del Juzgado Letrado de Hacienda al Jefe político municipal. Cartagena, 20-VIII-1833, A.G.N., Ministerio de lo Interior y relaciones exteriores t. I, doc. 32 f. 350.

${ }_{19}$ Informe de la Gobernación de la provincia al secretario del Interior. Cartagena, 28-VIII-1833. AGN, Ministerio de lo Interior y Relaciones Exteriores, t. I. doc. 32, f. 330 . El mismo día fueron liberados José Herrera, Valentín Espitaleta, Casimiro Calvo, Andrés Díaz y Juan Bartolomé por no hallarse causa contra ellos. Sobre el titulo militar de Pomares, AGN, República, Secretaría de Guerra y Marina, t. 489, f. 168.

${ }^{20}$ Informe de la Gobernación de la provincia al secretario del Interior. Cartagena, 28-VIII-1833. AGN, Ministerio de lo Interior y Relaciones Exteriores, t. I, doc. 32, f. 330.

${ }^{21}$ Informe que entrega Ramón Ripoll Juez Letrado de Hacienda al Jefe político. Cartagena, 19VIII-1833. AGN, Ministerio de lo Interior y Relaciones Exteriores, t. I, doc. 32, f. 342.

22 "Sumaria averiguación para aclarar asuntos de la mayor importancia para la seguridad pública, que tiene una trascendencia fatal con la subordinación y disciplina a las clases del ejército". AGN, Hemeroteca, Revista del Archivo Histórico Nacional, t. IV, No, 40, junio 1942, pp. 284-286. Para un desarrollo de este suceso ver LAsso, 2003, pp. 5-18, también CondE, 2009, cap. VII. 
la administración provincial estaba alerta por los sucesos acaecidos recientemente el 23 de julio en Bogotá, donde fue descubierta una conspiración que planeaba atentar contra el gobierno. Por esta razón unos días antes el gobernador de la provincia, José María Vezga, había enviado una carta al secretario de Estado del despacho de lo Interior comunicándole no sólo su respaldo al gobierno, sino también las medidas tomadas en la provincia para evitar que se produjera una conmoción similar a la de Bogotá:

Hasta ahora señor por las comunicaciones oficiales de usted solo resultan sesenta hombres y tal vez no resultaren más, pero una revolución que para trastornar la obra de la Nueva Granada no es la empresa de un puñado de hombres miserables. El español Zarela que se hallaba a la cabeza de la revolución es militar y su conducta no era viciosa. Suponer un hombre de esta clase y quererlo violentar el que emprende un proyecto semejante es pretender forzar la misma naturaleza. Redúcese pues que la obra de la revolución del 23 de julio merece mucha importancia por que ella supone a una complicación capaz de atentar al gobierno. No faltan descontentos señor, que en número considerable y como por otra parte reúnen dinero porque gozaron muchos de ellos de puestos y empleos distinguido ${ }^{23}$.

En este contexto, las denuncias sobre lo ocurrido en el bautizo tornado en conspiración tomaron fuerza y fueron recibidas por el gobierno provincial con preocupación.

\section{EL MITO DE LA CONSPIRACIÓN CONSTRUIDO CON AGUARDIENTE}

Aunque en el proceso judicial no se mencionan los oficios de todos los asistentes, entre los llamados a declarar por estar comprometidos en el suceso se encontraban un zapatero, un barbero y el citado sastre inglés apodado el "negrito Bartola"24. Las armas usadas -serrucho, cuchillos, martillos o cinceles- daban cuenta de que el dueño de la casa Venancio Escalante también era artesano y puede inferirse que gran parte del grupo de invitados eran compañeros de trabajo y amigos cercanos por el carácter familiar del evento. Dentro de la lógica de la sociabilidad tradicional de los pueblos, el resto de los invitados debían ser también conocidos como pudo ocurrir en el caso de los dos denunciantes Lauz y Pascual Alzamora. El primero fue invitado dos días antes del evento y no sólo no dijo sospechar de nada extraño cuando ello se produjo, sino que llevó con él a la reunión a su compadre Alzamora. Aunque una invitación extensa implicase la presencia de personajes ajenos al trabajo del anfitrión, la mayoría de los individuos que participaron en la fiesta posiblemente detentaban un común oficio y compartían una procedencia socioracial semejante.

${ }^{23}$ Informe que entrega Ramón Ripoll, Juez Letrado de Hacienda al Secretario de Estado del despacho del interior. AGN, Ministerio de lo Interior y Relaciones Exteriores, t. I, doc. 33, f. 351.

${ }^{24}$ Informe que entrega Ramón Ripoll, juez letrado de Hacienda al secretario de Estado del despacho de lo Interior. Cartagena, 20-VIII-1833. AGN, Ministerio de lo Interior y Relaciones Exteriores, t. I, doc. 32 , f. 350 . 
En una carta fechada el 16 de agosto de 1833, el mismo día del allanamiento y suscrita por el gobernador de la provincia de Cartagena, José María Vesga, al secretario de Estado del departamento del Interior, el primero explicaba lo sucedido en Cartagena relacionándolo con los eventos acaecidos en la capital del 23 de julio anterior:

No ha sido solamente en Bogota que ha querido conmoverse el orden público, tiñendo en sangre los días del año de treinta y tres, también en esta ciudad ha querido presentarse una escena sangrienta. En la noche del día 14, con pretexto de un bautismo se han reunido varios hombres desesperados en numero de cincuenta y tan desesperados que sin influjo, dinero ni combinación han pretendido robar, asesinar $\mathrm{y}$ tal vez destruir el gobierno. Ayer muy de mañana por denuncio que tuvo de dicha reunión en la noche anterior, el Señor Jefe Político, y de los brindis que hubo en la mesa, comenzaron a prenderse a los individuos concurrentes, y a la fecha casi todos, se hallan en la cárcel ${ }^{25}$.

El gobernador también dio cuenta de los individuos implicados en ella y anotó que en su mayoría eran conocidos "por sus hechos pasados, [y] pertenec[ían] al partido antiguo de serviles". La sorpresa para él era que algunos de los implicados habían tenido hasta ese momento una conducta conforme con los principios y las leyes:

Hay por otra parte muchos maestros de oficios que no necesitan del pillaje para proporcionarse el pan, aunque no faltan también inicuos, capaces de cometer todo atentado por su vagancia; pero sea lo que fuere, en lo que no cabe duda es que el orden público estuvo a punto de ser alterado y de que la sangre hubiese corrido ${ }^{26}$.

El gobernador reconocía que los participantes en la reunión tenían una militancia política que cobró un sentido sedicioso en el momento en que los acusados e insultados en el brindis eran todos liberales. ¿Se trataba de diferencias políticas e ideológicas? El mismo gobernador admitía que más allá de las reclamaciones socioraciales estaba en juego el control del poder político local que desde el año anterior pertenecía a los liberales. Sin embargo, también señaló que el movimiento conspirativo tenía un carácter popular ya que la mayoría de los implicados eran artesanos. Tras su apresamiento, la ciudad se mantenía en completa tranquilidad, a pesar de que aún no había sido capturado Cirilo Pomares, el principal acusado de conspiración. Pero en opinión del gobernador no existía el menor riesgo de que el movimiento sedicioso prosperase porque había sido obra de unos individuos del común que no fueron seguidos por ningún miembro notable de la sociedad:

${ }^{25}$ Carta de José María Vesga gobernador de la provincia al secretario de Estado del departamento de lo Interior. Cartagena, 16-VIII-1833. AGN, Ministerio de lo Interior y Relaciones Exteriores, t. I, doc. 32 , f. 351 .

${ }^{26}$ Carta de José María Vesga gobernador de la provincia al secretario de Estado del departamento de lo Interior. Cartagena, 16-VIII-1833. AGN, Ministerio de lo Interior y Relaciones Exteriores, t. I, doc. 32 , f. 351 . 
[...] en dicha reunión no hubo un solo hombre de reputación ni influjo, es bastante para creerse que tal ves el exceso del licor o de la desesperación, por que el trabajo no produce lo que el corazón desea, fue quizás quien promovió el intento del barbarismo mas refinado ${ }^{27}$.

El ministro aceptó la explicación del gobernador amparada en el "mito de la embriaguez", pero le solicitó que cuidase del orden público y procurara que desapareciesen todos los motivos de disgusto. Si bien el gobernador como administrador y representante del Estado en la provincia de Cartagena debía mostrar la buena marcha de su gestión -para evitar ser relevado del cargo-, tal vez la explicación que llevaba a convertir una celebración de bautizo en una conspiración y luego ésta en una manifestación de borrachos podía minimizar un descontento popular que no se solucionaba simplemente con penas de cárcel o de expulsión del territorio ${ }^{28}$. De hecho era consciente de que la desafección al régimen se debía a varias razones, una de ellas era la situación económica de la población que habitaba en la ciudad puerto y su provincia. La independencia había significado una destrucción relativa de las fuerzas productivas, cuya recuperación resultaba ardua debido a que buena parte de las batallas se habían librado en los campos de labranza, siendo los puertos atacados en innumerables ocasiones ${ }^{29}$. Finalizada la guerra e iniciado el proceso de reconstrucción económica del país, los sectores que experimentaron cierto crecimiento fueron los relacionados con la explotación de oro y el movimiento portuario. En el caso de la ciudad de Cartagena ello estuvo minimizado por las guerras internas. Sin embargo, si bien la crisis de la provincia revirtió negativamente en el estado de los sectores populares no parece que en la conspiración estudiada u otra de las descubiertas durante el período de estudio primase una motivación exclusivamente económica. Algunos de los implicados, por ejemplo, declararon ante los jueces, que su participación insurgente no se debía al descontento por su situación material, sino en relación a las marcadas diferencias socioraciales o a afinidades políticas.

En referencia a ello, los artesanos, el grupo protagonista de la mayoría de estos eventos y que por su tipo de organización gremial podía movilizarse colectivamente con mayor facilidad, parecía confiar para el logro de sus demandas más en los cauces políticos institucionales que en la acción grupal directa. De ahí que desarrollasen dos actuaciones: la solicitud formal y respetuosa al gobierno de medidas favorables a su estatus y actividad y la vinculación con las facciones políticas. Respecto a la primera sirva de ejemplo la representación que el gremio de artesanos de Cartagena envió a la Convención Nacional de 1831. A través de un escrito de petición solicitaba el

${ }^{27}$ Ibídem.

${ }^{28}$ Carta del secretario del juzgado de lo Interior y Exterior a José María Vesga gobernador de la provincia. Bogotá, 4-IX-1833. AGN, Ministerio de lo Interior y Relaciones Exteriores, Juzgado del Interior y Exterior, t. I, doc. 32, f. 24.

${ }^{29}$ Ver los ensayos reunidos en Calvo - Roca, 2002. Para Salomón Kalmanovitz la independencia trajo consigo el colapso del estado colonial, que mal que bien, funcionaba: "se pasó de los impuestos excesivos a prácticamente la inexistencia de estos, y los pocos que se cobraban recaían en el sector externo. Así, los nuevos gobiernos latinoamericanos nacieron débiles y no pudieron mantener el orden político", Kalmanovitz, 2006, pp. 161-183. 
fomento de este "clan" por medio de dos medidas: "el establecimiento de los juzgados de gremios, tales cuales existían antiguamente y la prohibición de importar las manufacturas que se fabrican en el país" ${ }^{\prime 3}$. Tal petición fue estudiada por el Consejo de Estado cuya respuesta fue que

En cuanto al primer punto el consejo ha opinado que no debe accederse a la medida propuesta por que los gremios están expresamente prohibidos, por el artículo 195 de la Constitución, i respecto del segundo ha sido de concepto, que estando desautorizado el poder ejecutivo por el decreto de la convención de 20 del presente año para reformar los aranceles de aduanas, se restrinja la importación de dichos artículos, recargándoles los derechos a fin de fomentar las artes i que el adoptar esta medida se pide de que el recargo no sea tan excesivo que alimente el contrabando y produzca un efecto contrario ${ }^{31}$.

Respecto a la vinculación con los partidos, terminado el proceso independentista muchos artesanos y milicianos convirtieron la política en su "actividad productiva" a fin de evitar la pauperización económica y ascender socialmente. Su asociación con los grupos políticos conllevaba actuar a su favor para que éstos no perdieran el poder y, por tanto, continuaran sosteniendo sus contratos o empleos oficiales ${ }^{32}$. En este sentido, las reclamaciones surgidas durante el brindis del bautizo no solo deben entenderse como una petición por la igualdad socioracial, sino también como un modo de infundir temor al gobierno y autoridades locales sobre posibles desórdenes y tumultos populares si sus protagonistas no encontraban resueltas sus necesidades profesionales y de estatus.

\section{LA "GUERRA DE RAZAS": ENTRE EL RUMOR Y EL TEMOR}

Las historias de las conspiraciones pretenden señalar que detrás de algunos sucesos siempre hay fuerzas oscuras: jesuitas, protestantes, masones y, en general, cualquier grupo opositor al gobierno. Para Karl Popper una teoría conspirativa de la sociedad

${ }^{30}$ Representación del gremio de artesanos de Cartagena presentó al Consejo de Estado. AGN, Sección República, Fondo Consejo de Estado, Legajo 2, f. 528.

${ }^{31}$ Respuesta del Consejo de Estado a representación del gremio de artesanos de Cartagena. Bogotá, 21-IV-1832. Biblioteca Luís Ángel Arango, Fondo Manuscritos, Miscelánea 562, f. 247.

${ }^{32}$ En las parroquias urbanas los notables tenían amplias influencias, llegando sus nombres a ser proclamados en las asambleas electorales de varias de ellas al mismo tiempo debido a que eran presentados por los alcaldes de distritos como vecinos de éstas a pesar de que la residencia era un requisito. En el caso de los comerciantes importadores, como Manuel Marcelino Núñez, como la frontera entre los negocios y la política era inexistente, su relación económica con artesanos y tenderos les permitía un acceso directo a la población y actuar de bisagra entre el gobierno y los sectores populares de cara a las elecciones. Así, no es de extrañar que en 1833 muchos de los tenderos también fuesen políticos como los casos de Manuel Medrano, José María Escudero, Juan José Nieto, José Matos (primo de Estevan García Matos) o Fernando de Pombo (había sido concejal en 1830). Relación de las tiendas y almacenes de licores extranjeros que hay en la ciudad. Tesorería de rentas provinciales. 1-XII-1833. Biblioteca Luís Ángel Arango, Fondo Manuscritos, Miscelánea 562, f. 2023. 
sería "la visión de que la explicación de un fenómeno social consiste en el descubrimiento de los hombres o grupos que están interesados en la ocurrencia de este fenómeno para que se lleve a cabo"33. La cualidad principal de esta representación de los procesos sociales es que asigna una intencionalidad oculta, tramada en las sombras a los procesos sociales vividos. A su vez, para que sea posible la construcción de un mito conspirativo es necesario e indispensable que el mensaje transmitido corresponda a los códigos sociales ya inscritos en el imaginario colectivo. Es decir, que ninguna empresa manipuladora puede esperar lograr sus objetivos cuando en los sectores de la opinión que pretende conquistar no exista una cierta posibilidad de disponibilidad ${ }^{34}$. En el caso estudiado, los fantasmas de la revolución haitiana, la exacerbación partidista o las diferencias raciales esparcidas con rumores y falsas informaciones contribuyeron a hacer verosímil la hipótesis conspirativa. Este paradigma interpretativo remite a una de las manifestaciones del imaginario mitológico, aquella que denuncia una conspiración maléfica que tiende a someter a los pueblos a la dominación de fuerzas oscuras y perversas. Raoul Girardet señala que más allá de la diversidad de su inspiración ideológica (racial, política, extraterrenal...), estos relatos presentan una sorprendente identidad de estructura, aunque las variantes narrativas sean incontables.

Atendiendo a la perspectiva teórica mencionada, la conspiración ha funcionado la mayor parte de las veces como un discurso de movilización política. Tradicionalmente, el recurso retórico del complot ha servido como una estratagema política de control y movilización, desde el ejercicio del poder y desde la oposición a é ${ }^{35}$. En este sentido, se entiende el recurso a la "guerra de razas" como un mecanismo dual: para amedrentar a la autoridad con la amenaza de un movimiento social que reinvirtiera el orden establecido o para permitir que ésta sofocara cualquier disidencia bajo el argumento de peligro de disolución de dicho orden. El uso de cualquier otro recurso no inscrito en el imaginario colectivo no hubiese tenido el impacto deseado tanto entre las filas del gobierno, como en el proceso de reclutamiento de adeptos. Por ello se entiende que el ministro de Estado hubiese prevenido al gobernador Vesga sobre la situación "cuando existen tantas desagradables prevenciones antiguas entre las diferentes clases de la sociedad, sobre las cuales debe recaer igualmente la protección de las leyes". Como resultaba previsible que apareciesen tales problemas, conminaba al gobernador a trabajar en la desaparición de esas diferencias ${ }^{36}$. En suma, la "guerra de razas" fue utilizada como una herramienta política para generar un clima de pánico entre los habitantes "blancos" que justificara la persecución gubernamental contra la oposición política. Con ello no solo se involucraba a amplios sectores de la población en los asuntos políticos, sino que se le hacía consciente de la capacidad y la acción coercitivas del Estado, en proceso de asentamiento a partir de las reformas judiciales (redacción de códigos, especialmente el penal de 1838) y militares (reglamentos, delimitación del fuero e incremento del apoyo logístico).

\footnotetext{
${ }^{33}$ Citado en: Skinner, 2001, pp. 93-111.

${ }^{34}$ Sobre el tema véase también ReszLER, 1981.

${ }^{35}$ Santoro, 2004. Para la difusión de las conspiraciones ver Bell - Bennion-Nixon, 2001, p. 133.

${ }^{36}$ Carta del Ministro de Estado al gobernador de la provincia de Cartagena. Bogotá, 4-IX-1833. A.G.N. Ministerio de lo Interior y Relaciones Exteriores, t. I, doc. 32, f. 24.
} 
La conspiración del 14 de agosto no prosperó porque careció de los elementos ya citados que debían caracterizarla. El gobierno capturó a más de cincuenta individuos que fueron procesados y acusados de conspiración. El cabecilla Pomares fue arrestado en Santa Marta y sentenciado a muerte, pena que más tarde se conmutó por una expatriación $^{37}$ de ocho años ${ }^{38}$. En este proceso resultó relevante que el reo fuera defendido por el abogado Agustín Núñez, quien era hijo de Manuel Marcelino Núñez. Este personaje, además de ser un actor de la independencia, comerciante connotado de la ciudad, con una amplia influencia política durante el decenio de 1830 y editor del periódico el Calentano donde criticaba la actitud de los "serviles" probolivarianos ${ }^{39}$, durante el brindis "conspirativo" había sido acusado por los conspiradores de mantener el control de la ciudad.

Durante el proceso, Agustín Núñez y Cirilo Pomares publicaron un "impreso indecente y algo sedicioso" con el cual recusaron a todos los ministros del tribunal y a los conjueces nombrados, bajo el argumento de que éstos debían estar legalmente impedidos por haber fallado en la misma causa contra los cómplices de Pomares. Según el abogado José María del Real, otro personaje de la independencia que en ese momento ya contaba con avanzada edad, pero de una vitalidad política fuerte en apoyo a Santander, le informaba a éste que:

Esta declaración ha escandalizado ha todos los hombres sensatos, pues ven que se ha abierto la puerta a la impunidad de los reos que se fugan dejando cómplices a quienes se les condena antes de que aquellos se aprehendan, como sucederá a Pomares, siendo el principal actor de la conspiración, en la que yo trasluzco, a través del aparente pretexto de clase en el día infundado, unas miras de conformidad con la conspiración de Bogotá, porque Ramírez es de los del partido, aunque el no se atrevió a presentar a los que quiso seducir su verdadero objeto, y así los atacó por su flanco débil que es la distinción de colores ${ }^{40}$.

${ }^{37}$ Biblioteca Luís Ángel Arango, Fondo Manuscritos. Miscelánea 562, f. 498.

${ }^{38}$ Informe de Ramón Ripoll juez letrado de Hacienda al ministro de lo Interior. Cartagena, 21X-1833. AGN, Ministerio de lo Interior y Relaciones Exteriores, t. I, doc. 30, fol. 298. Aunque según Gustavo Arboleda fue sentenciado a muerte por la corte de apelaciones del Magdalena y fusilado el 28-X-1833 junto a otro de sus cómplices. ArboledA, 1990, t. II, p 59.

${ }^{39}$ Manuel Marcelino Núñez, repatriado poco después de su expulsión por Bolívar, recomendó a las autoridades el destierro de los individuos desafectos al gobierno y por ser propagadores de ideas separatistas entre la juventud; en particular al redactor del periódico El Piringo, Vicente Piñeres, por ser uno de los más “desafectos". Carta de Manuel Marcelino Núñez al señor general Francisco de Paula Santander. Cartagena, 17-I-1834, en, CorTÁzAR, 1964 vol. IX, nº 3021, p. 94. El Piringo surgió en oposición a El Cachaco, dirigido por Manuel Marcelino Núñez, el periódico pedía medidas radicales al gobierno especialmente al vicepresidente José M. Castillo para que "expulsase del país a todos los desafectos del gobierno y aquellos que hayan conspirado contra éste, sin poder regresar nunca al país". El Calentano $\mathrm{n}^{\circ}$ 2. Cartagena, III-1834. Hemeroteca Biblioteca Nacional de Colombia.

${ }^{40}$ Carta de José María del Real a Francisco Santander. Cartagena, 25-X-1833. En CorTázar, 1964, t. V, no. 1740, p. 288. José María del Real era hijo de Juan del Real capitán de los Reales Ejércitos en el Reino de Galicia y Doña Rafaela Hidalgo y de Torre cartagenera. José María nació en Cartagena en 1767, estudió en el Colegio Real y Seminario de San Bartolomé de Santafé de Bogotá y se doctoró de abogado. Fue abogado de los Reales Consejos del Reino, alcalde de primer voto de Cartagena en 1808 y miembro de la Junta Suprema de Gobierno de Cartagena. Propietario de la Hacienda Santa Cruz, 
Estas constantes referencias a una "guerra de razas" hacían parte de los imaginarios sociales y políticos de los sectores notables e intermedios de la sociedad cartagenera y reflejaban a su vez una realidad social y política imposible de ocultar: las diferencias raciales estaban muy marcadas y chocaban con el ideario igualitario de la república ${ }^{41}$. En este sentido, no es casual que de un total de 119 cartas estudiadas, todas ellas dirigidas desde Cartagena al Presidente Santander, 19, es decir un 10\% de ellas hayan tenido informes sobre conspiraciones y "guerra de razas" intentadas en esa capital o la provincia. Y todas fueron escritas entre los años 1833 y 1836 por personas muy cercanas a Santander como José María Vezga, Pablo de Alcázar, José Hilario López, Antonio del Real y Juan José Nieto ${ }^{42}$.

La mayor preocupación de los gobiernos durante el período fue la relación entre "conspiradores" y "gentes de color" y, aunque en gran medida fue un mito justificador de la represión gubernamental, ambos fenómenos fueron intrínsecos al ambiente político. Mientras los problemas de la Nueva Granada eran reducidos por las elites gobernantes a problemas de integración del territorio y sus gentes al nuevo proyecto nacional, siendo las sediciones un asunto de "distinción de colores" o un "pretexto de clase", para la "gente de color" la cuestión residía en un problema de organización estatal y nacional en el que el tema de la autonomía de las provincias se relacionaba con impedir su exclusión del proyecto nacional. En este sentido, la mayoría de los movimientos catalogados como conspiraciones por el gobierno fueron expresiones y manifestaciones públicas organizadas por un corto número de personas, generalmente de los sectores populares y acaudillados por uno o varios intermediarios de las facciones políticas, para conseguir mediante la violencia política autonomías regionales y reconocimiento social. Como tales hechos cuestionaban las decisiones del gobierno central, las autoridades bogotanas pretendieron convertir el tema de la autonomía territorial en un asunto personal, o de facciosos, conspiradores, separatistas y federalistas, además de imprimirle una connotación racista y despectiva, como si únicamente se tratara de un problema de "colores"

murió en 1835. Sus hijos también tuvieron amplia influencia política: Tomás del Real y Cortines y el abogado Antonio del Real que fue rector de la Universidad de Cartagena en 1863. Restrepo, 1993, pp. $161-162$ y 591.

${ }^{41}$ Para lo de imaginarios sociales nos acogemos a lo propuesto por BACZKO,1994: "los imaginarios sociales son referencias específicas en el vasto sistema simbólico que produce toda colectividad y a través del cual ella "se percibe, se divide y elabora sus finalidades (Mauss). De este modo, a través de estos imaginarios sociales, una colectividad designa su identidad elaborando una representación de sí misma; marca la distribución de los papeles y las posiciones sociales; expresa e impone ciertas creencias comunes, fijando especialmente modelos formadores como el del "jefe", el del "buen súbdito", el del "valiente guerrero", el de "ciudadano", el del "militante", etc. Así, es producida una representación totalizante de la sociedad como un "orden", según el cual cada elemento tiene su lugar, su identidad y su razón de ser. [...] De esta manera, el imaginario social es una de las fuerzas reguladoras de la vida colectiva. Al igual que las demás referencias simbólicas, los imaginarios sociales no indican solamente a los individuos su pertenencia a una misma sociedad, sino que también definen, más o menos precisamente, los medios inteligibles de sus relaciones con ésta, con sus divisiones internas, con sus instituciones, etcétera", p. 28.

${ }^{42}$ Estas cartas fueron compiladas por CORTÁzAR, 1964, t. I al XXIV.

${ }^{43}$ CONDE, 2009, p. 248. 


\section{CONCLUSIONES}

A pesar de que nunca se llegó a probar que en dicha reunión hubiese "havido un plan premeditado o convinado para verificar la referida conspiración" ${ }^{44}$ se llevó a cabo una investigación que duró más de dos meses de la que resultó el apresamiento de más de cincuenta individuos, su juicio y la condena por el delito de conspiración de su supuesto líder, el capitán de milicias Cirilo Pomares. Con la decisión del gobierno de ver en una reunión una conspiración y, por tanto, detenidos y castigados ejemplarmente sus autores, se buscaba evitar complots auténticos. Esa lógica preventiva llevaba a ver conspiraciones en todas partes y explicaba por qué una celebración de bautizo podía terminar siendo una conspiración. Aunque ésta era en esencia una forma de expresión política de sectores sociales politizados y desligados del gobierno, fue utilizada por el mismo para asegurar la estabilidad de su administración a través de los mecanismos que la ley otorgaba: encarcelamientos, expatriaciones o ejecuciones de los detractores políticos. Ello dio lugar a una "sociedad de la sospecha" donde todo aquel que disentía era víctima de la persecución oficial por autor de complots, siendo la "guerra de razas" la argamasa justificativa de la producción de tales insurrecciones. Pero la invención de las conspiraciones no era contraria a que cuando éstas se producían sus protagonistas entendieran el proyecto sedicioso como un acto de lealtad política o un medio de obtener beneficios personales y grupales. Así unos participaban por su pertenencia a una red de favores encabezada por un dirigente notable, mientras otros lo hacían porque a través de un hecho político como éste lograban vincularse a esa red y obtener los beneficios consecuentes, sobre todo cuando ello permitía la integración en el escenario nacional de aquellos que la legislación excluía ${ }^{45}$.

Aunque el "mito de la conspiración" contribuyó a silenciar las voces disidentes, éstas tuvieron en la prensa y las elecciones otro modo de expresión. De hecho comicios y conspiraciones fueron de la mano. Como muestra una carta de 1834, en la cual el gobernador de la provincia de Cartagena informaba al ministro del Interior sobre la organización de "una conspiración por los enemigos del gobierno" a causa del resultado en las últimas elecciones en las que "no pudieron obtener sufragios para sus candidatos", los triunfos del gobierno en las urnas hicieron que la actividad política durante la década de 1830 estuviera llena de conspiraciones. El rumor, la sospecha, el motín y el pasquín -mecanismos ilegales en ese momento- se combinaron con las elecciones -mecanismo formal- y fueron practicados por distintos grupos políticos en un doble juego $\mathrm{y}$ en dependencia del grado y de la facilidad de acceso al poder.

${ }^{44}$ Informe del gobernador de la provincia de Cartagena al secretario del despacho de lo Interior. Cartagena, 23 de agosto de 1833. AGN, Ministerio de lo Interior y del Exterior, t. I. doc. 32, f. 342. En su respuesta el Secretario del Interior y relaciones exteriores también manifestó que el acontecimiento "no es de trascendencia alguna ni de sus antecedentes, ni por sus consecuencias", f. 342.

${ }^{45}$ Tampoco era banal para que las invitaciones a las reuniones políticas conllevaban bebida, comida, música y mujeres y para un buen número de hombres de la época ese festín resultaba cuando menos interesante. Ver Conde, 2004, pp. 191-217. 


\section{REFERENCIAS BIBLIOGRÁFICAS}

ArboledA, Gustavo

1990 Historia contemporánea de Colombia. Bogotá. Banco Central Hipotecario. Tomo II.

BACZKo, Bronislaw

1994 Los imaginarios sociales. Memorias y esperanzas colectivas. Buenos Aires. Nueva Visión.

BARALT, Guillermo

2006 Esclavos rebeldes: conspiraciones y sublevaciones de esclavos en Puerto Rico (1795-1873). Río Piedras. Ediciones Huracán.

Bell, David y BenNION-NiXon, Lee

2001 "The Popular Culture if Conspiracy/ the Conspiracy of Popular Culture". En PARISH - PARKer (eds.), pp. 133-153.

Bethell, Leslie (ed.)

1991 Historia de América Latina. Tomo V: La Independencia. Barcelona. Crítica.

Calvo, Haroldo y Roca, Meisel

2002 Cartagena de Indias en el siglo XIX. Bogotá. Universidad Jorge Tadeo Lozano.

Carmagnani, Marcelo (coord.)

1993 Federalismos latinoamericanos. México, Brasil, Argentina. México. Fondo de Cultura Económica.

Chiaramonte, José Carlos

2004 Nacióny Estado en Iberoamérica. Buenos Aires. Editorial Sudamericana.

Conde, Jorge

2004 "Representación política y prácticas electorales en el Caribe colombiano, 1820-1836". Anuario de Estudios Bolivarianos. Caracas. no 11, pp. 191-217.

2009 Buscando la Nación. Ciudadanía, clase y distinción racial en el Caribe colombiano. 1821-1855. Medellín. La carreta histórica.

Conde, Jorge y Monsalvo, Edwin

2010 "Referentes doctrinales en la independencia de la Nueva Granada". Revista Investigación y Desarrollo. Barranquilla. vol. 18: 2, pp. 17-31.

CORTÁZAR, Roberto

1964 Correspondencia dirigida al General Santander. Bogotá. Imprenta Nacional. Tomos I al XXIV.

GIRARDET, Raoul

1986 Mythes et mithologique politique. Histoire. Paris. Editions du Senil. 
Grasses, Pedro

1997 La conspiración de Gual y España y el Ideario de la Independencia. Caracas. Archivo Histórico Nacional.

Guerra, François - Xavier

1988 México: del Antiguo Régimen a la Revolución. México. Fondo de Cultura Económica. Tomo I.

HeLG, Aline

2004 Liberty \& Equality in Caribbean Colombiano. 1770-1835. Chapell HillLondon. The University of North Carolina Press.

Holton, Isaac

1981 La Nueva Granada: Veinte meses en los Andes. Bogotá. Banco de la República.

Kalmanovitz, Salomón

2006 "El PIB en la Nueva Granada en 1800: Auge colonial, estancamiento republicano". Revista de Economía institucional. Bogotá. vol. 8. n 15, pp. 161-183.

2008 "Consecuencias económicas de las independencias en Colombia". Revista de Economía institucional. Bogotá. vol. 10. nº 19, pp. 207-233.

LAsso, Marixa

2003 "Haití como símbolo republicano popular en el Caribe colombiano:

Provincia de Cartagena (1811-1828)". Revista Historia Caribe. Barranquilla. vol. III. $\mathrm{n}^{\circ} .8$, pp. 5-18.

LOCKHART, James y SchWARTz, Stuart

1992 América Latina en la edad moderna. Madrid. Akal.

MARCHENA, Juan

1982 La institución militar en Cartagena de Indias 1700-1810. Sevilla. Escuela de Estudios Hispanoamericanos.

1990 "The Social World of the Military Peru and New Granada: The Colonial Oligarchies in Conflict, 1750-1810". En FisHer, John - KuETE, Allan - Mcfarlane, Anthony (comps.). Reform and Insurrection in Bourbon New Granada and Peru. Baton Rouge. Louisiana State University Press.

Monsalvo, Edwin

2006 "A la caza de votos". Prácticas electorales en la provincia de Cartagena, 1821-1843”. Revista Anuario de Historia Regional y de las Fronteras. Bucaramanga. $n^{\circ}$. 10, pp. 51-66.

PARrish, Jane y PARKer Martin (eds.)

2001 The Age of Anciety. Conspiration Theory and the Human Science. Sociological Review Monograph. Oxford. Blackwell. 
PRADO, Luís

2005 Rebeliones en la provincia: la guerra de los supremos en las provincias suroccidentales y nororientales granadinas 1839 - 1842. Tesis de Maestría en Historia. Universidad Industrial de Santander. Bucaramanga.

Restrepo, Pastor

1993 Genealogías de Cartagena de Indias. Bogotá. Instituto Colombiano de Cultura Hispánica.

RESZLER, André

1981 Mythes politiques modernes. Paris. Presses Universitaires de France.

SAntoro, Pablo

2004 "La deriva de la sospecha. Conspiraciones ovnis y riesgo". Revista Nómadas. Madrid. n. 9, pp. 1-16

SKINNER, Jonathan

2001 "Taking Conspiracy Seriously: Fantastic Narrative and Mr Gray the Pant afrikanist in Monserrat”. En PARRISH - PARKER (eds.), pp. 93-111.

Troconis de Vengoechea, Ermila

1997 "Doña Joaquina Sánchez de España". Boletín de la Academia Nacional de la Historia. Caracas. no. 319, pp. 3-21.

Vidal, Antonino y Monsalvo, Edwin

2008 Las provincias de la costa Caribe en la construcción de la nación colombiana. Los informes de los gobernadores. Informe final de investigación. Departamento de Investigaciones y proyectos. Universidad del Norte. 